\title{
SÕNA
}

\section{KUPPAMA JA KUPATAMA}

\author{
LEMBIT VABA
}

$\mathrm{T}$

egusõnal kuppama : kupata '(kupatamisel) keema' ja selle tuletisel kupatama : kupatada 'toiduaineid soolase, kibeda või hapu maitse vähendamiseks või mürkainete kõrvaldamiseks veidi aega rohkes vees keetma; kedagi (sunniviisil) kuhugi saatma, ajama või midagi tegema panema; kiiresti sõitma, kihutama, tuhatnelja ajama; tormama, jooksma; (kuhugi) loopima, paiskama, virutama, ajama (puid ahju; lund taevast alla vms); (löömise, peksmise kohta)' (EKSS 2: 577-579) pole usutavat etümoloogiat. Alljärgnevalt uurin verbitüve levikut, tuletushargmikku ja semantikat ning võimalikku etümoloogilist seost balti keeleainesega.

kuppama 'kupatama, eelkeetma, keema panema; sooja käes tursuma või kokku kuivama; paistetama; pinnale kerkima, üles kobrutama; kihutama; (taga) ajama; loopima; hoogsalt midagi tegema' kohta on hajateateid kogu Põhja-Eesti alalt (EMS IV/16: 54-55). Refleksiiv- resp. intransitiivse kontinuatiivliitega - $u$ - kuppuma '(eel)keema; kupatama; kuumas paisuma; läppuma' kohta on enam teateid Lõuna-Eestist (EMS IV/16: 56). Andrus Saareste „Eesti keele mõistelises sõnaraamatus" on kuppama esitatud järgmistes mõisterühmades: KÜPSEMA (EKMS 2: 340), RIKNEMA (EKMS 3: 618), SOOJUS (EKMS 3: 889), TÕUSMA (EKMS 4: 137) ja VAHT (EKMS 4: 319).

kupatama '(korraks) keema laskma; põletama; hautama; paistetama; kedagi kuhugi saatma, ajama või midagi tegema panema; kiiresti sõitma, kihutama; tormama, jooksma; loopima, virutama' on ülemaaliselt tuntud (EMS IV/16: 46-48), kuuludes kirjakeeles 10000 sagedama sõna hulka (Kaalep, Muischnek 2002). Rannikumurdest on lisaks registreeritud kupastama ja võru murdest kupahtama 'kupatama' (EMS IV/16: 46, 45). Vändrast kirja pandud regilauludes on kupatama sünonüümiasuhtes tegusõnadega seenetama, hallitama, päevatama: Lähe ei kuhja kupatama, / Seest ei kuhja seenetama, / Alt ei kuhja hallitama, I Pealt ei kuhja päevatama (ERA). Saareste sõnaraamatus esineb kupatama mõisterühmades AJAMA (EKMS 1: 103), KÜPSETAMA (EKMS 2: 344), PEKSMA (EKMS 3: 113), SEEDIMA (EKMS 3: 750), SOENDAMA (EKMS 3: 873).

kuppama ja kupatama alltähendused 'kihutama, kiiresti sõitma jt; (taga) ajama, kedagi (sunniviisil) kuhugi saatma, ajama jt' kirjeldavad tegevusi, mis assotsieeruvad tormiliselt kulgeva keemis- ja keetmisprotsessiga. Sarnase semantilise väljaga on nt lt vārìt 'keetma; keema; kiiresti käima, jooksma, sõitma; lööma, loopima; ajama, sundima' (Tēzaurs). Alltähendused 'seedima' ja 'peksma' on võib-olla laenulist päritolu, vrd vn вapumb 'keetma (toitu); seedima', vn mrd 'peksma, lööma, piitsa andma' (SRNG 4: 54), vrd keetma tähenduses 'lööma' (EKMS 2: 761 LÖÖMA). 
Alates Gösekeni „Manuductiost” on kuppama ja kupatama kohta teateid kõigis vanemais leksikograafilistes allikates: 'auffgesotten Milch [kuumaks või keema aetud piim]' / kupputut Pihm (Göseken 1660: A 295); Kuppama 'aufquellen, aufkochen', Kuppatama 'neutr. aufkochen', Kuppatut Piim 'aufgekochte Milch' (Vestring 1998 [1710-1730]: 101); kuppatama 'aufkochen act. und neutr.', kuppatud piim 'abgekochte Milch' (Helle 1732: 125); kuppama 'aufquellen, aufkochen' r., kuppatama 'aufquellen, aufkochen act. auch neutr.' r., d., kuppatud piim 'abgekochte Milch' r. (Hupel 1780: 195). Rohkelt teavet sõnapere kohta leidub Wiedemanni sõnaraamatus (1973 [1893]: 412-413): kuppama : kupata kuppada 'aufkochen, aufquellen (intrans., auch trans.)', kupastama, kupatama 'aufkochen, aufquellen (transit.), abbrühen, fig. prügeln, (O) rennen', ihu on kupatud 'der Körper ist mürbe von Prügeln', ära kupatama 'verbrühen, mit heissem Wasser verbrennen, fig. verdauen', päev on kalad kupatand 'die Fische sind durch die Sonnenwärme verdorben'.

Verbist kuppama lähtub verbaalsubstantiiv kupp : kupa 'Aufkochen, Aufquellen [keemaajamine, (eel)keetmine, kupatamine]': kapsad on kupal 'der Kohl ist zum Aufquellen, Bähen aufgesetzt [kapsad on hauduma pandud]', vesi on kupal 'das Wasser fängt an zu kochen [vesi on keema hakanud]' (Wiedemann 1973 [1893]: 413; EKMS 2: 340, 341 KÜPSEMA, 346 KÜPSETAMA; 3: 143 piim). kupa- 'kupatatud, keedetud' on rea liitsõnade täiendosis: kupakartul 'koorega keedetud kartul', kupapiim 'ahjus keedetud (ternes)piim' (EKSS 2: 577; EKMS 3: 143 PIIM; vt lisa EMS IV/16: 45 sub kupa-). kupatama-verbist lähtub us-liiteline verbaalsubstantiiv kupatus : kupatuse 'kupatamine; kraam, krempel; kamp, jõuk' (EKSS 2: 578), mrd ka kupats : kupatse 'kupatamine', kupatsed 'poolkeenud herned', kupats : kupatsi '(lamba peade/jalgade/siseelundite) kupatusvesi' (vt Neetar 1990: 171), kupats : kupatse, seene-k. 'Pilzkocher (ein Spottname) [seenekeetja (pilkenimi)]' (Wiedemann 1973 [1893]: 412).

Ilmne eestipärasus on Kalliveres (ka: Kalliviere, Eesti Ingeri) kõneldud soome murdest registreeritud kupauttaa: pittà kupauttà silakkoi 'peab kupatama silku [s.o leotama kuivatatud silke keevas vees]'; kupahuusta: kiehuvassa veessä kupahù kala 'keevas vees kupatud [kuivatatud] kala', jo on kupahùssèt 'juba on kupatatud [kuivatatud kalad]' (SMS).

Julius Mägiste (EEW 4: 1050) on oletanud, et need eesti verbid on arvatavasti („wahrscheinlich”) tuletised nimisõnast kupp : kupa 'õhumull, muhk, nupp'. See kõhklemisi esitatud seisukoht ei ole pädev, sest ei suuda katvalt seletada kõnealuste verbide semantilise hargmiku tekke- ega arengulugu. Mägiste seisukohta kordab ka etümoloogiasõnaraamat (EES: 193 sub kuppama). Vahemärkusena lisan: juurtüvest kupp : kupa ilmselt lähtuv ja teiseselt kuppama-verbiga assotsieeruv juhtum on nt mrd kuplema : kupelda 'mulle ajama' ( $\Leftarrow k u p p a-+-(e) l e-$, vt EEW 4: 1052 sub kupp $\left.{ }^{1}\right)$, nt VJg vesi ‘kupleb kui ruttu juakseb ja kui kieb (EMS IV/16: 52). Rahvaetümoloogia seob kupal 'keema hakkamas' ja kupp : kupu, vrd nt Jõe vesi on kupal, kupud `kerkivad. Veel on Mägiste väitnud, et Eestiga piirnevast läti murdest Ruhjas (lt Rūjiena) talletatud indoeuroopa taustaga verbi kupêt tähendus 'keetma' on eesti laen. Väide rajaneb piiratud materjalil ja on ekslik. Alljärgnevalt näitan, et tegemist on vastassuunas liikunud sõnalaenuga.

Eritletavat juhtumit keerustab asjaolu, et ilmselgelt tuleb arvestada etümoloogiliselt taustalt eri läti laenualustega $k u p a-$ ja $k \bar{u} p a-$ ning viimase juurde 
kuuluva murdelise variandiga kupa-, mis balti keeltes on nii häälikuliselt kui ka tähenduslikult omavahel tihedalt põimunud.

Eeskätt pean silmas läti murdekeelest registreeritud verbe kupêt 'keema', kupināt 'kupatama (nt seeni), keeva veega kõrvetama, üle valama (nt rupskeid), hautama' (ME 2: 317; EH 1: 676; Rağe 1969: 11; Bušmane 2007: 283), vrd ld kupéti (kùpa kùpia, kupéjo) 'üle ääre keema' (LKŽ). Need verbid kuuluvad sõnaperre, kuhu lt kûpêt intr 'suitsema, suitsu ajama, tossama, aurama; tolmama; lõhnama / rauchen, dampfen, qualmen, stäuben', mrd kûpt (kûp kûpst, kûpa) intr 'suitsema, aurama, paksu suitsu välja ajama, tossama; hallitama / qualmen, dampfen, rauchen; schimmeln', kûpinât tr 'paksu suitsu välja ajama, tossutama, suitsutama (kala, liha) / qualmen, dampfen machen, rau-

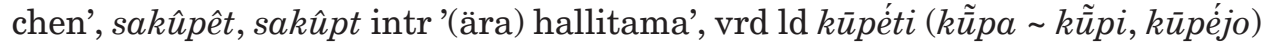
intr 'kõvasti keema, üle ääre voolama; kerkima, käärima'. Balti verbitüvel on vasteid ka teistes indoeuroopa keeltes, nt sl *kypěti: vn кunémb 'keema, pulbitsema' (ME 2: 337; ME 3: 660; EH 1: 684; LLVV 4: 493-494, 498; LEV 1: 445; LKŽ; LEW 1: 325 sub kvẽpti; ALEW 1: 545-546 sub kvẽpti; Smoczyński 2016: 644).

Lühivokaalne tüvevariant ( $u$ pro $\bar{u}$ ) on teisene, see on tekkinud häälikuliselt ja mõisteliselt lähedase balti sõnapere mõjul, kuhu kuuluvad nt lt mrd kupt (kup, kupa) intr 'kokku minema, kalgenduma, käärima; kuhjuma', (sa)kupis: (sa)k. piens 'kohupiim', kupât intr, frekv 'kalgenduma, tõusma, kerkima', kupinât fakt '(hapupiima) kuumutades kalgendama, kohupiima, juustu tegema; rahutu olema, möllama, tormitsema': $k$. pienu 'kohupiima saamiseks hapendatud piima kuumutama', kupināt(ai)s, kūpināts jt: $k$. piens 'kohupiim / gekäste Milch', atkupinât pienu 'hapendatud ja kooritud piima soojas ahjus hoidma: eraldub vadak ja piim saab tummise, meeldiva maigu', kupinâtiês refl 'kalgenduma, kokku minema, paksenema (kohupiima kohta); kerkima (taigen), paisuma', vrd ld kùpti (kùpsta kùpa, kùpo) 'tõusma, kerkima, käärima', kupétis refl 'kerkima (taigen)', kùpinti 'kuumutades (hapupiima) kalgendama' (ME 1: 169, ME 2: 317, 318, 319; LLVV 4: 494; LVDA: 161-165; Bušmane 2007: 278-285; LEV 1: 445-446 sub kupls; LKŽ; Smoczyński 2016: 645). Sellest sõnaperest on laenatud lvK kuppô : kuppù̀b 'kalgenduma', kuppôn: $k$. sēmd'a 'kalgendunud piim, kohupiim', kup̌pànttô, kup̌pintttô 'kalgendada' (Kettunen 1938: 166b; Suhonen 1973: 144). Samast laenualusest lähtub ka Sjögreni sõnaraamatus (LDW) leiduv rahutut merd kirjeldav verb kupūb: meŕ $k$. 'kui valgeharjalised lained tõusevad / wenn die weissgipflingen Wellen sich mehren', mis etümoloogilistes käsitlustes on jäänud tähelepanuta. Vahetult sama läti laenualusega on võib-olla seotud juba eespool nimetatud ee kupapiim, kui see tõepoolest tähistab nn ahjupiima, s.o ternespiima, mis kuumutamisel kalgendub suure valgusisalduse tõttu kergesti juustutaoliseks massiks; vrd veel kui `lehmä tuleb ‘piimä `keideti kuppa piimä Vai (EMS IV/16: 45). Vastavaid teateid on vähe ja need on raskesti määratletava sisuga. Liivi verbe on asjaomases kirjanduses kõrvutatud eesti kupatama-verbiga, mis on eksitav. 


\section{Kirjandus}

ALEW = Altlitauisches etymologisches Wörterbuch. Kd 1-3. (Studien zur historisch-vergleichenden Sprachwissenschaft 7.) Koost ja toim Wolfgang Hock, Elvira-Jūlia Bukevičiūtè, Christiane Schiller, Rainer Fecht, Anna Helene Feulner, Eugen Hill, Dagmar S. Wodko. Hamburg: Baar-Verlag, 2015.

B u š m a n e, Brigita 2007. Piena vārdi: piena produktu nosaukumi latviešu valodā. Rīga: LU Latviešu valodas institūts.

EES = Eesti etümoloogiasõnaraamat. Koost ja toim Iris Metsmägi, Meeli Sedrik, Sven-Erik Soosaar. Peatoim I. Metsmägi. Tallinn: Eesti Keele Sihtasutus, 2012.

$\mathrm{EEW}=$ Julius Mägiste, Estnisches etymologisches Wörterbuch. Kd 1-12. Helsinki: Finnisch-Ugrische Gesellschaft, 2000.

EH = Jānis Endzelīns, Edīte Hauzenberga, Papildinājumi un labojumi K. Mülenbacha Latviešu valodas vārdnīcai. Kd 1-2. Rīgā: Lettischen Kulturfonds / Grāmatu apgāds, 1934-1946.

EKMS = Andrus Saareste, Eesti keele mõisteline sõnaraamat. Kd 1-4. Dictionnaire analogique de la langue estonienne. Avec un index pourvu des traductions en français. (Eesti Teadusliku Seltsi Rootsis väljaanne 3.) Stockholm: Vaba Eesti, 1958-1963.

EKSS = Eesti keele seletav sõnaraamat. Kd 1-6. „Eesti kirjakeele seletussõnaraamatu” 2., täiendatud ja parandatud trükk. Toim Margit Langemets, Mai Tiits, Tiia Valdre, Leidi Veskis, Ülle Viks, Piret Voll. Eesti Keele Instituut. Tallinn: Eesti Keele Sihtasutus, 2009. http://www.eki.ee/dict/ekss/ (2. X 2019).

EMS = Eesti murrete sõnaraamat I-. Tallinn: Eesti Keele Instituut 1994-.

Göseken, Heinrich 1660. Manuductio ad Linguam Oesthonicam. Anführung zur Öhstnischen Sprache. Reval: Gedruckt und verlegt von Adolph Simon / Gymnasij Buchdr.

Helle, Anton Thor 1732. Kurtzgefaßte Anweisung Zur Ehstnischen Sprache, in welcher mitgetheilet werden I. Eine Grammatica, II. Ein Vocabvlarivm, III. Proverbia, IV. Anigmata, V. Colloqvia. Halle: Gedruckt bey Stephan Orban.

Hupel, August Wilhelm 1780. Ehstnische Sprachlehre für beide Hauptdialekte den revalschen und den dörptschen; nebst einem vollständigen Wörterbuch. Herausgegeben von August Wilhelm Hupel. Riga und Leipzig: J. F. Hartknoch.

Ka a le p, Heiki-Jaan, M u i s c h n e k, Kadri 2002. Eesti kirjakeele sagedussõnastik. Tartu: Tartu Ülikooli Kirjastus. http://www.cl.ut.ee/ressursid/sagedused/index. php?lang=et (25. X 2019).

Kettunen, Lauri 1938. Livisches Wörterbuch mit grammatischer Einleitung. (Lexica Societatis Fenno-Ugricae V.) Helsinki: Suomalais-Ugrilainen Seura.

LDW = Joh. Andreas Sjögren's Livisch-deutsches und deutsch-livisches Wörterbuch. Im Auftrage der Kaiserlichen Akademie der Wissenschaften bearbeitet und mit einer historisch-ethnographischen Einleitung versehen von Ferdinand Joh. Wiedemann. St. Petersburg: Kaiserliche Akademie der Wissenschaften, 1861. http://www.eki.ee/dict/ldw/ldw.html (25. X 2019).

LEV = Konstantīns Karulis, Latviešu etimoloǵijas vārdnīca. Kd 1-2. Rīga: Avots, 1992.

LEW = Ernst Fraenkel, Litauisches etymologisches Wörterbuch. Kd 1-2. Heidelberg: Carl Winter, Universitätsverlag, Göttingen: Vandenhoeck \& Ruprecht, 1962-1965. 
LLVV = Latviešu literārās valodas vārdnīca. Kd 1-8. Rīga: Zinātne, 1972-1996.

LVDA = Brigita Bušmane, Benita Laumane, Anna Stafecka, Latviešu valodas dialektu atlants. Leksika. [Rīga:] Zinātne, 1999.

$\mathrm{ME}=\mathrm{K}$. Mīlenbacha Latviešu valodas vārdnīca. Kd 1-4. Toim Jānis Endzelīns. Rīgā: Lettischen Bildungsministerium / Lettischen Kulturfonds, 1923-1932.

Neet a r, Helmi 1990. Deverbaalne nominaaltuletus eesti murretes. Toim Valdek Pall. Tallinn: Eesti TA Eesti Keele Instituut.

Ra ǵ e, Silvija 1969. 4. apvidvārdu aptauja. Aizguvumi no Baltijas somu valodām. Rīga: Zinātne.

SRNG = Slovar' Russkih Narodnyh Govorov. Kd 1-. Leningrad: Nauka, 1965-. [Словарь русских народных говоров 1-. Ленинград: Наука, 1965-.]

Suhonen, Seppo 1973. Die jungen lettischen Lehnwörter im Livischen. (Suomalais-Ugrilaisen Seuran toimituksia 154.) Helsinki: Suomalais-Ugrilainen Seura.

Vestring, Salomo Heinrich 1998 [1710-1730]. Lexicon Estonico Germanicum. Tartu: Eesti Kirjandusmuuseum.

W i e d e m a n n, Ferdinand Johann 1973 [1893]. Eesti-saksa sõnaraamat. Estnischdeutsches Wörterbuch. Neljas, muutmata trükk teisest, Jakob Hurda redigeeritud väljaandest. Vierter unveränderter Druck nach der von Jakob Hurt redigierten Auflage. Tallinn: Valgus.

\section{Võrgumaterjalid}

ERA = Eesti regilaulude andmebaas. http://www.folklore.ee/regilaul/andmebaas (25. X 2019).

LKŽ = Lietuvių kalbos žodynas. Kd 1-20, 1941-2002. Elektroninio varianto I leidimas 2005. http://www.lkz.lt (25. X 2019).

S moczyński, Wojciech 2016. Słownik etymologiczny języka litewskiego. Wydanie drugie, poprawione i znacznie rozszerzone. Na prawach rękopisu. https:// rromanes.org/pub/alii/Smoczyński\%20W.\%20Słownik\%20etymologiczny\%20 języka\%20litewskiego.pdf (25. X 2019).

SMS = Suomen murteiden sanakirja. http://kaino.kotus.fi/sms (25. X 2019).

Tēzaurs = Tēzaurs. Skaidrojošā un sinonīmu vārdnīca. https://tezaurs.lv (25. X 2019).

\section{Kasutatud lühendid}

fakt $=$ faktitiiv frekv $=$ frekventatiiv intr $=$ intransitiivne $; \mathbf{m r d}=$ murdeline keelend; refl $=$ refleksiiv; $\mathbf{t r}=$ transitiivne.

\section{Keeled, murded ja murrakud}

ee = eesti keel; $\mathbf{d}$. = der dörptsche Dialekt (tartu keel); Jõelähtme; ld = leedu keel; lt = läti keel; lvK = kuraliivi keel; r. = der revalsche Dialekt (tallinna keel); sl = algslaavi keel; Vaivara; VJg = Viru-Jaagupi; vn = vene keel. 
Lembit Vaba (snd 1945), PhD, Läti Teaduste Akadeemia välisliige (Roosikrantsi 6, 10119 Tallinn),phorest45@gmail.com

\section{kuppama and kupatama}

Keywords: Estonian, Finnish, Baltic languages, Latvian loanwords, lexical history

So far, neither the Estonian verb kuppama : kupata 'to boil (of a liquid or sth immersed in boiling liquid)' nor its derivative kupatama 'to boil foodstuff in abundant water for a short time' have been offered a plausible etymology. The article investigates the areal distribution of the verb stem, its derivation network and semantics, as well as its possible etymological relation with Latvian. The existing suggestion that the Estonian verbs have been derived from the noun kupp : kupu 'air bubble, bump, knob' is not valid for failing to provide a full story to capture the emergence and development of the semantic network of the words in question. The article provides the Estonian verb stem with a Latvian etymology, considering etymologically different loan stems such as kupa- and kūpa- with its dialectal variant kupa-, which are all closely intertwined in the Baltic languages, both phonetically and semantically: Latv kupêt 'to boil (intrans.)', kupināt 'to scald sth (e.g. mushrooms) with boiling water, wash over (e.g. offal), stew', which belong to the same word family as Latv kûpêt 'to smoke, emit smoke, fume, steam etc.', kûpt 'to smoke, steam, emit thick smoke, fume etc.'. The stem variant with a short vowel ( $u$ pro $\bar{u}$ ) is secondary, born under the influence of a phonetically and conceptually close Baltic word family represented, for example, by Latv kupât 'to congeal, rise, heave etc.'. This word family is the source for the Courland Livonian words kuppô : kup̌pùb 'to congeal (intrans.)' and kup̌pànttầ 'to congeal (trans.)'. The comparison of the Livonian verbs with the Estonian verb kupatama 'to boil foodstuff in abundant water for a short time' sometimes found in literature, is misleading.

Lembit Vaba (b. 1945), PhD, Foreign Member of the Latvian Academy of Sciences (Roosikrantsi 6, 10119 Tallinn), phorest45@gmail.com 